\title{
ATP-sensitive inwardly rectifying potassium channel modulators alter cardiac function in honey bees
}

\author{
Scott T. O’Neal ${ }^{\mathrm{a}}$, Daniel R. Swale ${ }^{\mathrm{b}}$, Jeffrey R. Bloomquist ${ }^{\mathrm{c}}$, Troy D. Anderson ${ }^{\mathrm{d}}$
}

a Department of Entomology, Virginia Tech, Blacksburg, VA, USA

b Department of Entomology, Louisiana State University AgCenter, Baton Rouge, LA, USA

${ }^{\mathrm{C}}$ Department of Entomology and Nematology, Emerging Pathogens Institute, University of Florida, Gainesville, FL, USA

d Department of Entomology, University of Nebraska, Lincoln, NE, USA

Corresponding Author: Scott T. O’Neal (onealst@vt.edu)

\section{Abstract}

ATP-sensitive inwardly rectifying potassium ( $\left.\mathrm{K}_{\mathrm{ATP}}\right)$ channels couple cellular metabolism to the membrane potential of the cell and play an important role in a variety of tissue types, including the insect dorsal vessel, making them a subject of interest not only for understanding invertebrate physiology, but also as a potential target for novel insecticides. Most of what is known about these ion channels is the result of work performed in mammalian systems, with insect studies being limited to only a few species and physiological systems. The goal of this study was to investigate the role that $\mathrm{K}_{\text {ATP }}$ channels play in regulating cardiac function in a model social insect, the honey bee (Apis mellifera), by examining the effects that modulators of these ion channels have on heart rate. Heart rate decreased in a concentration-dependent manner, relative to controls, with the application of the $\mathrm{K}_{\text {ATP }}$ channel antagonist tolbutamide and $\mathrm{K}_{\text {ATP }}$ channel blockers barium and magnesium, whereas heart rate increased with the application of a low concentration of the $\mathrm{K}_{\text {ATP }}$ channel agonist pinacidil, but decreased at higher concentrations. Furthermore, pretreatment with barium magnified the effects of tolbutamide treatment and eliminated the effects of pinacidil treatment at select concentrations. The data presented here confirm a role for $\mathrm{K}_{\text {ATP }}$ channels in the regulation of honey bee dorsal vessel contractions and provide insight into the underlying physiology that governs the regulation of bee cardiac function.

\section{Keywords}

Honey bee; heart rate; ion channels; $\mathrm{K}_{\mathrm{ATP}}$ channels; tolbutamide; pinacidil

\section{Introduction}

The honey bee (Apis mellifera), like other insects, relies upon an open circulatory system for the transport of nutrients, immune factors, waste products, and signaling molecules throughout the body cavity. The insect circulatory system also functions in thermoregulation, ventilation, and the maintenance of homeostasis. Furthermore, studies have shown that the insect immune and circulatory systems can closely interact to control infections (King and Hillyer, 2012; Sigle and Hillyer, 2016), highlighting the 
extensive level of integration between cardiac function and the insect immune response. The insect circulatory system is driven by a central pulsatile organ known as the dorsal vessel, which is situated along the dorsal midline and spans the length of the insect. The abdominal portion of the dorsal vessel serves as the functional equivalent of the vertebrate heart and uses peristaltic action to force hemolymph through the thoracic dorsal vessel, which is commonly referred to as the aorta (Jones, 1977). Openings known as ostia are located along the length of the heart, allowing hemolymph to be drawn into the vessel and pumped in an anterograde fashion through the aorta in the direction of the head (Miller, 1985). With the aid of accessory pulsatile organs, hemolymph is circulated throughout the extremities of the insect (Pass, 2000). The periodic reversal of heartbeat, and subsequent reversal of hemolymph flow, has been described in a number of different insects at varying life stages (Gerould, 1933; Wasserthal, 1996), but has not been found to occur in bees (Miller, 1997). Although historically a subject of much debate, a growing body of evidence supports the idea that the origin of insect heartbeat is myogenic and not neurogenic in nature, as the heart is able to generate contractions in the absence of neural input (Miller, 1985, 1997; Slama and Lukas, 2011). There is strong evidence, however, that demonstrates a role for a neural component in the regulation of heart rate and directionality of insect cardiac function (Heinrich, 1970; Miller, 1985), including bees (Schwab et al., 1991). A considerable amount of research has examined the role that various ion channels (Gu and Singh, 1995), classical neurotransmitters (Johnson et al., 1997; Zornik et al., 1999), and cardiomodulatory peptides (Cuthbert and Evans, 1989) play in regulating insect heart rate. The biogenic amine octopamine has been identified as one of the primary insect neuromodulators (Roeder, 1999) and is known to have a cardioacceleratory role in insects (Zornik et al., 1999), including bees (Papaefthimiou and Theophilidis, 2011). While examples of parallel studies can be found in a variety of other insect species, especially those of medical importance (Hillyer et al., 2015), very few studies have been conducted to explore the regulation of bee cardiac activity.

Cardiac muscle contractions are the direct result of action potentials, which are generated by voltage-gated ion channels located in the cellular plasma membrane. Inwardly-rectifying potassium $\left(\mathrm{K}_{\mathrm{ir}}\right)$ channels play an important role in modulating this activity by stabilizing the resting membrane potential of the cell and mediating inward potassium transport across the membrane at potentials less than the potassium equilibrium rate constant $\left(E_{k}\right)$ (Reimann and Ashcroft, 1999). One member of the family of $\mathrm{K}_{\mathrm{ir}}$ channels, the ATP-sensitive inwardly rectifying potassium $\left(\mathrm{K}_{\mathrm{ATP}}\right)$ channel, is regulated by the level of nucleotides present in the cytosol and consequently provides an important link between the metabolic state of the cell and its membrane excitability (Hibino et al., 2010). Mammalian $\mathrm{K}_{\mathrm{ATP}}$ channels are heteromeric octamers composed of four pore-forming $\mathrm{K}_{\mathrm{ir}}$ channel subunits (Kir6.1 or Kir6.2) and four regulatory sulfonylurea receptor (SUR) subunits (SUR1 or SUR2) (Ashcroft and Gribble, 1998) and have been described in a variety of different tissues, including heart, skeletal muscle, vascular smooth muscle, pancreas, as well as brain (Ashcroft, 1988). Relative to the extensive body of knowledge concerning mammalian $\mathrm{K}_{\mathrm{ir}}$ channels, little is known about insect $\mathrm{K}_{\text {ir }}$ 
channels, and even less about $\mathrm{K}_{\mathrm{ATP}}$ channels. What is known about the insect $\mathrm{K}_{\text {ir }}$ channel gene family is due in large part to the versatility of Drosophila as a model organism, as fruit flies have proven a valuable tool in the identification and characterization of novel ion channels (Doring et al., 2002). Genes encoding insect $\mathrm{K}_{\mathrm{ir}}$ channel subunits were first identified in the fruit fly (Drosophila melanogaster) (Doring et al., 2002) and this information was used to subsequently identify related genes in the yellow fever mosquito (Aedes aegypti) (Piermarini et al., 2013), the African malaria mosquito (Anopheles gambiae) (Raphemot et al., 2014a), and the bedbug (Cimex lectularius) (Mamidala et al., 2013). Although they are present in insects, $\mathrm{K}_{\mathrm{ir}}$ channel genes do not appear to be as abundant or diverse as they are in mammals. The genome of the fruit fly, for example, has been found to encode three $\mathrm{K}_{\mathrm{ir}}$ channel family genes (Doring et al., 2002), while five have been identified in the yellow fever mosquito genome (Piermarini et al., 2013), which is considerably fewer than the sixteen $\mathrm{K}_{\text {ir }}$ channel family genes belonging to seven subfamilies that have been identified in humans (Raphemot et al., 2014a). The characterization of $\mathrm{K}_{\mathrm{ir}}$ channel genes in disease vector mosquitoes has focused almost entirely upon on their role in renal function, where they appear to be critical for urine production and potassium homeostasis (Raphemot et al., 2013), in order to evaluate their potential exploitation as a target for novel insecticides (Raphemot et al., 2014b; Rouhier et al., 2014; Swale et al., 2016). Research using fruit flies as a model to investigate the insect antiviral immune response has demonstrated that $\mathrm{K}_{\text {ATP }}$ channels appear to play an evolutionarily conserved role in mediating the survival of insects and mammals alike during viral infections (Croker et al., 2007). This finding has led to the further observation that insect coronary $\mathrm{K}_{\text {ATP }}$ channels have a function in modulating antiviral RNA interference (RNAi), presumably by facilitating tissue specific regulation of innate immune response mechanisms by the cellular environment of the heart (Eleftherianos et al., 2011).

While putative $\mathrm{K}_{\mathrm{ir}}$ channel family genes can be found in the Apis mellifera genome, based on comparisons to Drosophila melanogaster or Aedes aegypti $\mathrm{K}_{\mathrm{ir}}$ channel gene sequences, no data have been published that describe a functional characterization of the expressed proteins or explore their role in the honey bee or any other hymenopteran. This represents a major knowledge gap, given the significant interest in managed bee colony losses (Neumann and Carreck, 2010; Ratnieks and Carreck, 2010), concerns over the impact of pesticide usage on pollinator health (Mullin et al., 2010), and the growing understanding of the detrimental effects that viruses have on colony health and survival (Cox-Foster et al., 2007; Johnson et al., 2009; McMenamin and Genersch, 2015). The research described here will begin to address this gap by investigating the relationship between $\mathrm{K}_{\mathrm{ATP}}$ channels and cardiac function in an agriculturally and economically important pollinator and model social insect. As a first step to exploring the physiological role of $\mathrm{K}_{\mathrm{ATP}}$ channels in bee cardiac function, we demonstrated the effects of $\mathrm{K}_{\text {ATP }}$ channel modulators on bee heart rate, examining the $\mathrm{K}_{\mathrm{ATP}}$ channel antagonist tolbutamide, agonist pinacidil, and known blockers barium $\left(\mathrm{Ba}^{2+}\right)$ and magnesium $\left(\mathrm{Mg}^{2+}\right)$. Tolbutamide is a sulfonamide drug known as a sulfonylurea that has been used in the treatment of type 2 diabetes due to its ability to 
stimulate insulin production in the beta cells of the pancreas (Ashcroft and Ashcroft, 1992). In mammalian systems, tolbutamide blocks $\mathrm{K}_{\text {ATP }}$ channels by binding to the SUR1 subunit, resulting in depolarization of the cell membrane (Kaubisch et al., 1982). Tolbutamide treatment has been found to increase mortality and viral RNA expression in virus infected fruit flies (Croker et al., 2007; Eleftherianos et al., 2011). Pinacidil is a cyanoguanidine drug that is used as an antihypertensive due to its vasodilatory properties through relaxation of vascular smooth muscle (Arrigoni-Martelli and Finucane, 1985). Pinacidil opens $\mathrm{K}_{\text {ATP }}$ channels by binding to the mammalian SUR2 subunit, resulting in hyperpolarization of the cell membrane (Uhde et al., 1999). Treatment with pinacidil has been shown to confer protective effects against viral infections in fruit flies, increasing survival and decreasing viral load via modulation of the antiviral immune response through an as yet undetermined mechanism (Eleftherianos et al., 2011). The sulfonylureas and cyanoguanidines are thought to have distinct, but closely associated, binding sites in mammals (Uhde et al., 1999), supporting the idea that the sites are coupled in a negative allosteric fashion (Bray and Quast, 1992). Whether or not this is true for insects remains unknown, as the SUR selectivity of these compounds has not been examined in an insect model. $\mathrm{Ba}^{2+}$ and $\mathrm{Mg}^{2+}$ were selected since $\mathrm{Ba}^{2+}$ is known to selectively block $\mathrm{K}_{\text {ir }}$ channels at low- to mid-micromolar concentrations and $\mathrm{Mg}^{2+}$ is capable of physically blocking $\mathrm{K}_{\text {ir }}$ channels (Armstrong et al., 1982; Armstrong and Taylor, 1980; Horie et al., 1987; Matsuda et al., 1987). The results of this work demonstrate that $\mathrm{K}_{\text {ATP }}$ channel modulators have an observable effect on honey bee heart rate that supports their expected physiological role in bee cardiac function.

\section{Methods}

\subsection{Subjects}

European honey bees (Apis mellifera) were used for all experiments. Bee colonies were maintained according to standard beekeeping practices using commercial hives that were housed in an apiary located at the Virginia Tech Price's Fork Research Facility (Blacksburg, VA). For all laboratory experiments, worker bees were collected from brood frames during typical foraging times to ensure collection of predominately nurse bees. Bees kept in the lab overnight were housed at $32{ }^{\circ} \mathrm{C}$ with a relative humidity of $50-80 \%$ and provided ad libitum access to honey and a $50 \%$ solution of sucrose in water.

\subsection{Dissection and heart rate assays}

Visualization of the honey bee heart and measurements of heart rate were conducted as previously described (O'Neal and Anderson, 2016). To summarize, each bee was dissected to remove the dorsal abdominal wall and expose the dorsal vessel. The dorsal vessel was bathed in an isotonic solution ( $1 / 4$ strength Ringer's solution; Sigma Aldrich) and the heartbeat was allowed to stabilize. Baseline heart rate was measured for 1 min prior to the addition of any test compounds or vehicle controls, then measured 
again 2 min later. Test compounds were dissolved in dimethyl sulfoxide (DMSO) and then diluted in $1 / 4$ strength Ringer's solution to the desired concentration, ensuring a consistent vehicle of $1 \%$ DMSO in $1 / 4$ strength Ringer's solution. Changes in heart rate were reported as percent change relative to the baseline heart rate, measured in beats per minute (BPM).

\subsection{Concentration response experiments}

The aim of this experiment was to assess the effects of $\mathrm{K}_{\text {ATP }}$ channel modulators on bee heart rate by evaluating a range of concentrations for each modulator. The modulators that were tested include the $\mathrm{K}_{\text {ATP }}$ channel antagonist tolbutamide, the $\mathrm{K}_{\text {ATP }}$ channel agonist pinacidil, as well as the cations $\mathrm{Ba}^{2+}$ and $\mathrm{Mg}^{2+}$. All test compounds were obtained from Sigma-Aldrich at the highest purity available and prepared and delivered in $1 \%$ DMSO in $1 / 4$ strength Ringer's solution, which served as the vehicle control. Test compounds were evaluated across a range of concentrations, from the low nanomolar to the high millimolar, in order to establish a profile for each compound. Each treatment group had a sample size of 10 individual bee dissections.

\subsection{Barium pretreatment experiment}

The aim of this experiment was to examine the hypothesis that tolbutamide and pinacidil modulate heart rate by acting upon cardiac $\mathrm{K}_{\text {ATP }}$ channels. Also studied was whether or not pretreatment with a low concentration of the $\mathrm{K}_{\mathrm{ir}}$ channel blocker $\mathrm{Ba}^{2+}$ would alter the effects of treatment with tolbutamide or pinacidil. $\mathrm{Ba}^{2+}$ was chosen over $\mathrm{Mg}^{2+}$ due to its effectiveness at lower concentrations and its increased specificity for $K_{i r}$ channels. Based on the results of the previous experiment, $1 \mu \mathrm{M} \mathrm{Ba}^{2+}$ was selected to test against $100 \mu \mathrm{M}$ tolbutamide and $100 \mathrm{nM}$ pinacidil. The concentration of $\mathrm{Ba}^{2+}$ used was the highest concentration that did not produce a significant effect on heart rate. The concentrations of tolbutamide and pinacidil were selected due to their significant effect on heart rate and the relatively low variability of that concentration. The protocol for the dissection and heart rate assay was followed as described, with one exception. Following dissection and visualization, the heart was bathed in either vehicle or vehicle containing $1 \mu \mathrm{M} \mathrm{Ba}^{2+}$. The protocol then continued as previously described, with the application of $100 \mu \mathrm{M}$ tolbutamide, $100 \mathrm{nM}$ pinacidil, or vehicle control following 1 min of baseline heart rate assessment. Each treatment group had a sample size of 12 individual bee dissections.

\subsection{Statistical Analysis}

All analyses and calculations were conducted using GraphPad Prism 7 (GraphPad Software, Inc., La Jolla, CA). The half maximal effective concentration $\left(E_{50}\right)$ was determined using a four parameter nonlinear regression equation. All results are expressed as the mean $+/$ - standard deviation (SD). Each treatment group was subjected to a D'Agostino-Pearson test for normality $(P<0.05)$ and not all groups were found to come from a normally distributed population; therefore, nonparametric tests were used for all analyses. For both the concentration-response experiments and the 
blocking experiment, each treatment group was compared to the vehicle control using a Mann-Whitney test $(P<0.05)$.

\section{Results}

\subsection{Concentration response experiments}

Tolbutamide produced a concentration-dependent effect on heart rate, as the application of increasing concentrations of tolbutamide resulted in greater decreases in heart rate with no evidence of an increase at any concentration (Fig 1). A significant decrease in heart rate relative to the vehicle control was observed at concentrations of 3 $\mu \mathrm{M}$ and above (Mann-Whitney test; $P<0.05$ ) with maximal effect (complete cessation of heart beat) being observed at $1 \mathrm{mM}$. Nonlinear regression estimated an $\mathrm{EC}_{50}$ of 0.18 mM (95\% Cl: $0.14-0.23$ mM; Hill Slope: 0.99; $R^{2}$ : 0.79). Pinacidil, however, produced a biphasic effect on heart rate, as the application of a high nanomolar concentration increased heart rate, while the application of concentrations in the high micromolar range and above decreased heart rate (Fig 1). A significant increase in heart rate relative to the vehicle control was observed at $100 \mathrm{nM}$ (Mann-Whitney test; $P<0.0001$ ), while a significant decrease was observed at concentrations of $100 \mu \mathrm{M}$ and above (Mann-Whitney test; $P<0.001$ ) with maximal effect being observed at $1 \mathrm{mM}$. Due to the biphasic response of the heart to pinacidil treatment, the $\mathrm{EC}_{50}$ value was calculated using the $3 \mu \mathrm{M}$ and greater treatments. Nonlinear regression estimated an $\mathrm{EC}_{50}$ of 0.31 $\mathrm{mM}$ (95\% Cl: $0.24-0.39 \mathrm{mM}$; Hill Slope: $1.84 ; \mathrm{R}^{2}$ : 0.76). Mean baseline heart rate (+/SD) across treatment groups measured $101.9+/-5.0$ BPM for tolbutamide and $98.2+/-$ 3.5 BPM for pinacidil.

The cations $\mathrm{Ba}^{2+}$ and $\mathrm{Mg}^{2+}$ had uniformly inhibitory effects on bee heart rate. $\mathrm{Ba}^{2+}$ produced a concentration-dependent effect on heart rate, as the application of increasing concentrations of $\mathrm{Ba}^{2+}$ resulted in greater decreases in heart rate (Fig 1). A significant decrease in heart rate relative to the vehicle control was observed at concentrations of $10 \mu \mathrm{M}$ and above (Mann-Whitney test; $P<0.0001$ ) with maximal effect being observed at $1 \mathrm{mM}$. Nonlinear regression estimated an $\mathrm{EC}_{50}$ of $0.62 \mathrm{mM}$ (95\% Cl: $0.39-0.96 \mathrm{mM}$; Hill Slope: $\left.0.62 ; \mathrm{R}^{2}: 0.81\right) . \mathrm{Mg}^{2+}$ also produced a concentration-dependent effect on heart rate, as the application of increasing concentrations of $\mathrm{Mg}^{2+}$ resulted in greater decreases in heart rate (Fig 1). A significant decrease in heart rate relative to the vehicle control was observed at concentrations of $30 \mathrm{mM}$ and above (Mann-Whitney test; $P<0.0001$ ) with maximal effect being observed at $100 \mathrm{mM}$. Nonlinear regression estimated an $\mathrm{EC}_{50}$ of $27.29 \mathrm{mM}(95 \% \mathrm{Cl}: 23.04-$ $31.39 \mathrm{mM}$; Hill Slope: 2.77; $\mathrm{R}^{2}:$ 0.88). Mean baseline heart rate (+/- SD) across treatment groups measured 101.1 +/- 4.1 BPM for $\mathrm{Ba}^{2+}$ and 100.6 +/- 4.1 BPM for $\mathrm{Mg}^{2+}$.

\subsection{Barium pretreatment experiment}

Pretreatment with $\mathrm{Ba}^{2+}$ magnified the effects of tolbutamide treatment and eliminated the effects of pinacidil treatment (Fig 2). Pretreatment with $1 \mu \mathrm{M} \mathrm{Ba}^{2+}$ followed by treatment with vehicle resulted in no significant change in heart rate relative to the 
vehicle control. Pretreatment with vehicle followed by either $100 \mu \mathrm{M}$ tolbutamide or 100 $\mathrm{nM}$ pinacidil resulted in either a significant decrease or increase in heart rate, respectively, with effects comparable to those observed in the previous experiment (Mann-Whitney test; $P<0.001$ ). Pretreatment with $1 \mu \mathrm{M} \mathrm{Ba}^{2+}$ followed by treatment with $100 \mu \mathrm{M}$ tolbutamide resulted in a complete cessation of heart beat, comparable to the effect of $1 \mathrm{mM}$ tolbutamide treatment, making the decrease in heart rate significant relative to both the vehicle control and the tolbutamide control (Mann-Whitney test; $P<$ 0.001). Pretreatment with $1 \mu \mathrm{M} \mathrm{Ba}{ }^{2+}$ followed by treatment with $100 \mathrm{nM}$ pinacidil resulted in no significant increase in heart rate relative to the vehicle control, but a significant difference relative to the pinacidil control (Mann-Whitney test; $P<0.001$ ). Mean baseline heart rate (+/- SD) across treatment groups measured 98.6 +/- 5.7 BPM.

\section{Discussion}

Here we have demonstrated that tolbutamide and pinacidil significantly alter cardiac activity in honey bees, most likely through their interaction with $\mathrm{K}_{\text {ATP }}$ channels expressed in the plasma membrane of the dorsal vessel, though interaction with $\mathrm{K}_{\text {ATP }}$ channels in the mitochondrial membrane are also possible and cannot be ruled out by this work. Direct application of the $\mathrm{K}_{\mathrm{ATP}}$ channel antagonist tolbutamide to the exposed bee heart resulted in a concentration dependent decrease in heart rate, whereas the agonist pinacidil produced a biphasic response with an increase in heart rate at low concentrations and a decrease at higher concentrations. Direct comparison of these results to other insect systems is not possible due to the lack of comparable studies using invertebrate models. Interestingly enough, however, comparisons can be made with vertebrate systems. The biphasic response of the changes in bee heart rate that was observed following treatment with pinacidil supports earlier findings that pinacidil inhibited both the amplitude and velocity of isolated rabbit heart contractions in a biphasic manner (Nielsen et al., 1989). This not only suggests that the drug may have more than one site of action, but also supports the idea of an evolutionarily conserved role for $\mathrm{K}_{\mathrm{ATP}}$ channels in cardiac function. Despite the obvious differences between the tubular invertebrate heart and the compact mammalian heart, both have been shown to originate from a similar set of progenitor cells and subsequently develop under the regulation of a similar suite of genes (Bodmer, 1995; Ocorr et al., 2007). Furthermore, both hearts function in a myogenic fashion with insect hearts having been shown to possess a pacemaker regulatory node with an analogous function to the sinoatrial or atrioventricular nodes (Bodmer et al., 2005; Slama, 2006). Thus, the idea that $\mathrm{K}_{\text {ATP }}$ channels might function in such a conserved fashion between insects and mammals should not be surprising, especially given that treatment with the $\mathrm{K}_{\mathrm{ir}}$ channel blockers $\mathrm{Ba}^{2+}$ and $\mathrm{Mg}^{2+}$ also resulted in a concentration dependent decrease in heart rate. When applied in combination, pretreatment with a low concentration of $\mathrm{Ba}^{2+}$ had a significant effect on subsequent treatments with synthetic modulators, amplifying the effect of tolbutamide and eliminating the effect of pinacidil on heart rate. The amplified effect of the combined $\mathrm{Ba}^{2+}$ and tolbutamide treatment is suggestive of blocking activity at more than one site. The loss of effect with the combined $\mathrm{Ba}^{2+}$ and pinacidil treatment 
suggests that $\mathrm{Ba}^{2+}$ is preventing pinacidil induced potassium flow. This is in keeping with patch clamp studies conducted in canine ventricular myocytes that found pinacidil induced current was reduced by $\mathrm{Ba}^{2+}$ treatment (Arena and Kass, 1989). This evidence suggests that the observed effects are the result of interactions with cardiac $\mathrm{K}_{\text {ATP }}$ channels, rather than off-target effects on heart rate, and supports an evolutionarily conserved role for $\mathrm{K}_{\text {ATP }}$ channels in the cardiac function of bees.

These findings are significant as they highlight the important role that $\mathrm{K}_{\mathrm{ATP}}$ channels serve in regulating and maintaining proper cardiac function. It is important to point out that this work was conducted using dissected heart preparations that disconnected the dorsal vessel from the central nervous system and other inputs that typically influence heart physiology in vivo. Nevertheless, such studies are important for evaluating many aspects of cardiac function, and offer certain advantages over a whole animal approach (O'Neal and Anderson, 2016). $\mathrm{K}_{\mathrm{ir}}$ channels modulate action potentials by stabilizing the resting membrane potential of the cell, and $\mathrm{K}_{\mathrm{ATP}}$ channels do so in response to changes in the metabolic state of the cellular environment. In the heart, this can significantly change the heart rate of the insect, subsequently having an effect on physiological processes such as thermoregulation and circulation (Miller, 1997). This also raises intriguing questions regarding the role that $\mathrm{K}_{\mathrm{ATP}}$ channels play in maintaining homeostasis and the regulation of the antiviral innate immune response (Croker et al., 2007). The treatment of fruit flies with the $K_{\text {ATP }}$ channel antagonist tolbutamide has been demonstrated to have a significant effect on the outcome of a viral infection, resulting in more rapid mortality and greater accumulation of virus in the insect, whereas treatment with the agonist pinacidil conferred some protective benefits to infected flies (Eleftherianos et al., 2011). Is the modulation of the insect's heart rate, or the blocking of the insect's ability to modulate heart rate in response to changes in the cellular environment, responsible in whole or in part for this observation, or is there some other connection between $\mathrm{K}_{\mathrm{ATP}}$ channel regulation and the innate immune response? This question represents a valuable area of future research in the honey bee, given the serious impact that viral infections have on the health of managed bee colonies. A better understanding of this relationship is also important given the potential use of $\mathrm{K}_{\text {ATP }}$ channels as novel targets for insecticides (Raphemot et al., 2014b; Rouhier et al., 2014; Swale et al., 2016), as the effects of pesticide exposure on pollinator health remains a topic of considerable discussion. Even if $\mathrm{K}_{\text {ATP }}$ channel modulators do not prove to be immediately toxic to beneficial insects, there is certainly room for concern that interactions with the innate immune response would result in sublethal effects that could impact the overall health of the colony in the long term. In conclusion, the data presented here provide evidence for the role of $\mathrm{K}_{\mathrm{ATP}}$ channels in the regulation of honey bee cardiac activity and demonstrate the effect that $\mathrm{K}_{\text {ATP }}$ channel modulators have on heart rate. This work sets the stage for continuing investigation of the physiological role of $\mathrm{K}_{\text {ATP }}$ channels in bees. This work also raises questions about the possibility of evolutionarily conserved interactions between $\mathrm{K}_{\text {ATP }}$ channels and the bee antiviral immune response and provides cautionary insight into the impact that future insecticides targeting $\mathrm{K}_{\text {ATP }}$ channels might have on pollinator health. 


\section{Acknowledgments}

The authors would like to thank Jennifer R. Williams for her technical assistance with the heart dissections.

\section{Funding}

This material is based upon work that is supported by the National Institute of Food and Agriculture, United States Department of Agriculture, under award number 2017-6701126048. The funders had no role in study design, data collection and analysis, decision to publish, or preparation of the manuscript.

\section{Author contributions}

Conceptualization: STO, DRS, JRB, TDA. Investigation: STO. Formal Analysis: STO, TDA. Funding Acquisition: STO, TDA. Original Draft Preparation: STO. Review and Editing: STO, DRS, JRB, TDA.

\section{Author competing interests}

The authors have no competing interests to declare.

\section{References}

Arena, J.P., Kass, R.S., 1989. Enhancement of potassium-sensitive current in heart cells by pinacidil. Evidence for modulation of the ATP-sensitive potassium channel. Circ Res 65, 436-445.

Armstrong, C.M., Swenson, R.P., Jr., Taylor, S.R., 1982. Block of squid axon K channels by internally and externally applied barium ions. J Gen Physiol 80, 663-682.

Armstrong, C.M., Taylor, S.R., 1980. Interaction of barium ions with potassium channels in squid giant axons. Biophys J 30, 473-488.

Arrigoni-Martelli, E., Finucane, J., 1985. Pinacidil. Cardiovascular Drug Reviews 3, 133151.

Ashcroft, F.M., 1988. Adenosine 5'-triphosphate-sensitive potassium channels. Annu Rev Neurosci 11, 97-118.

Ashcroft, F.M., Gribble, F.M., 1998. Correlating structure and function in ATP-sensitive K+ channels. Trends Neurosci 21, 288-294.

Ashcroft, S.J., Ashcroft, F.M., 1992. The sulfonylurea receptor. Biochim Biophys Acta $1175,45-59$.

Bodmer, R., 1995. Heart development in Drosophila and its relationship to vertebrates. Trends Cardiovasc Med 5, 21-28. 
Bodmer, R., Wessells, R., Johnson, E., 2005. 2.6 Heart Development and Function. Comprehensive molecular insect science, 199.

Bray, K.M., Quast, U., 1992. A specific binding site for K+ channel openers in rat aorta. J Biol Chem 267, 11689-11692.

Cox-Foster, D.L., Conlan, S., Holmes, E.C., Palacios, G., Evans, J.D., Moran, N.A., Quan, P.L., Briese, T., Hornig, M., Geiser, D.M., Martinson, V., vanEngelsdorp, D., Kalkstein, A.L., Drysdale, A., Hui, J., Zhai, J., Cui, L., Hutchison, S.K., Simons, J.F., Egholm, M., Pettis, J.S., Lipkin, W.I., 2007. A metagenomic survey of microbes in honey bee colony collapse disorder. Science 318, 283-287.

Croker, B., Crozat, K., Berger, M., Xia, Y., Sovath, S., Schaffer, L., Eleftherianos, I., Imler, J.L., Beutler, B., 2007. ATP-sensitive potassium channels mediate survival during infection in mammals and insects. Nat Genet 39, 1453-1460.

Cuthbert, B.A., Evans, P.D., 1989. A Comparison of the Effects of Fmrfamide-Like Peptides on Locust Heart and Skeletal-Muscle. Journal of Experimental Biology 144, 395-415.

Doring, F., Wischmeyer, E., Kuhnlein, R.P., Jackle, H., Karschin, A., 2002. Inwardly rectifying $\mathrm{K}+(\mathrm{Kir})$ channels in Drosophila. A crucial role of cellular milieu factors Kir channel function. J Biol Chem 277, 25554-25561.

Eleftherianos, I., Won, S., Chtarbanova, S., Squiban, B., Ocorr, K., Bodmer, R., Beutler, B., Hoffmann, J.A., Imler, J.L., 2011. ATP-sensitive potassium channel (K(ATP))dependent regulation of cardiotropic viral infections. Proc Natl Acad Sci U S A 108, 12024-12029.

Gerould, J.H., 1933. Orders of insects with heart-beat reversal. Biol Bull-Us 64, 424431.

Gu, G.G., Singh, S., 1995. Pharmacological analysis of heartbeat in Drosophila. J Neurobiol 28, 269-280.

Heinrich, B., 1970. Nervous control of the heart during thoracic temperature regulation in a sphinx moth. Science 169, 606-607.

Hibino, H., Inanobe, A., Furutani, K., Murakami, S., Findlay, I., Kurachi, Y., 2010. Inwardly Rectifying Potassium Channels: Their Structure, Function, and Physiological Roles. Physiol Rev 90, 291-366.

Hillyer, J.F., Estevez-Lao, T.Y., Mirzai, H.E., 2015. The neurotransmitters serotonin and glutamate accelerate the heart rate of the mosquito Anopheles gambiae. Comp Biochem Physiol A Mol Integr Physiol 188, 49-57. 
Horie, M., Irisawa, H., Noma, A., 1987. Voltage-dependent magnesium block of adenosine-triphosphate-sensitive potassium channel in guinea-pig ventricular cells. $\mathrm{J}$ Physiol 387, 251-272.

Johnson, E., Ringo, J., Dowse, H., 1997. Modulation of Drosophila heartbeat by neurotransmitters. J Comp Physiol B 167, 89-97.

Johnson, R.M., Evans, J.D., Robinson, G.E., Berenbaum, M.R., 2009. Changes in transcript abundance relating to colony collapse disorder in honey bees (Apis mellifera). P Natl Acad Sci USA 106, 14790-14795.

Jones, J.C., 1977. The circulatory system of insects. Thomas, Springfield, III. ;.

Kaubisch, N., Hammer, R., Wollheim, C., Renold, A.E., Offord, R.E., 1982. Specific receptors for sulfonylureas in brain and in a beta-cell tumor of the rat. Biochem Pharmacol 31, 1171-1174.

King, J.G., Hillyer, J.F., 2012. Infection-induced interaction between the mosquito circulatory and immune systems. PLoS Pathog 8, e1003058.

Mamidala, P., Mittapelly, P., Jones, S.C., Piermarini, P.M., Mittapalli, O., 2013. Molecular characterization of genes encoding inward rectifier potassium (Kir) channels in the bed bug (Cimex lectularius). Comp Biochem Physiol B Biochem Mol Biol 164, 275-279.

Matsuda, H., Saigusa, A., Irisawa, H., 1987. Ohmic conductance through the inwardly rectifying $\mathrm{K}$ channel and blocking by internal Mg2+. Nature 325, 156-159.

McMenamin, A.J., Genersch, E., 2015. Honey bee colony losses and associated viruses. Current Opinion in Insect Science.

Miller, T.A., 1985. Structure and physiology of the circulatory system, in: Kerkut, G.A. (Ed.), Comprehensive insect physiology, biochemistry and pharmacology, pp. 289-353.

Miller, T.A., 1997. Control of circulation in insects. Gen Pharmacol 29, 23-38.

Mullin, C.A., Frazier, M., Frazier, J.L., Ashcraft, S., Simonds, R., Vanengelsdorp, D., Pettis, J.S., 2010. High levels of miticides and agrochemicals in North American apiaries: implications for honey bee health. PLoS One 5, e9754.

Neumann, P., Carreck, N.L., 2010. Honey bee colony losses. J Apicult Res 49, 1-6.

Nielsen, C.B., Mellemkjaer, S., Nielsen-Kudsk, F., 1989. Pinacidil uptake and effects in the isolated rabbit heart. Pharmacol Toxicol 64, 14-19.

O'Neal, S.T., Anderson, T.D., 2016. Dissection and Observation of Honey Bee Dorsal Vessel for Studies of Cardiac Function. e55029. 
Ocorr, K., Perrin, L., Lim, H.Y., Qian, L., Wu, X., Bodmer, R., 2007. Genetic control of heart function and aging in Drosophila. Trends Cardiovasc Med 17, 177-182.

Papaefthimiou, C., Theophilidis, G., 2011. Octopamine--a single modulator with double action on the heart of two insect species (Apis mellifera macedonica and Bactrocera oleae): Acceleration vs. inhibition. J Insect Physiol 57, 316-325.

Pass, G., 2000. Accessory pulsatile organs: evolutionary innovations in insects. Annu Rev Entomol 45, 495-518.

Piermarini, P.M., Rouhier, M.F., Schepel, M., Kosse, C., Beyenbach, K.W., 2013. Cloning and functional characterization of inward-rectifying potassium (Kir) channels from Malpighian tubules of the mosquito Aedes aegypti. Insect Biochem Molec 43, 7590.

Raphemot, R., Estevez-Lao, T.Y., Rouhier, M.F., Piermarini, P.M., Denton, J.S., Hillyer, J.F., 2014a. Molecular and functional characterization of Anopheles gambiae inward rectifier potassium (Kir1) channels: a novel role in egg production. Insect Biochem Mol Biol 51, 10-19.

Raphemot, R., Rouhier, M.F., Hopkins, C.R., Gogliotti, R.D., Lovell, K.M., Hine, R.M., Ghosalkar, D., Longo, A., Beyenbach, K.W., Denton, J.S., Piermarini, P.M., 2013. Eliciting renal failure in mosquitoes with a small-molecule inhibitor of inward-rectifying potassium channels. PLoS One 8, e64905.

Raphemot, R., Rouhier, M.F., Swale, D.R., Days, E., Weaver, C.D., Lovell, K.M., Konkel, L.C., Engers, D.W., Bollinger, S.F., Hopkins, C., Piermarini, P.M., Denton, J.S., 2014b. Discovery and characterization of a potent and selective inhibitor of Aedes aegypti inward rectifier potassium channels. PLoS One 9, e110772.

Ratnieks, F.L., Carreck, N.L., 2010. Clarity on honey bee collapse? Science 327, 152153.

Reimann, F., Ashcroft, F.M., 1999. Inwardly rectifying potassium channels. Curr Opin Cell Biol 11, 503-508.

Roeder, T., 1999. Octopamine in invertebrates. Prog Neurobiol 59, 533-561.

Rouhier, M.F., Raphemot, R., Denton, J.S., Piermarini, P.M., 2014. Pharmacological validation of an inward-rectifier potassium (Kir) channel as an insecticide target in the yellow fever mosquito Aedes aegypti. PLoS One 9, e100700.

Schwab, E.R., Chilson, R.A., Eddleman, C.D., 1991. Heartbeat Rate Modulation Mediated by the Ventral Nerve Cord in the Honey-Bee, Apis-Mellifera. Journal of Comparative Physiology B-Biochemical Systemic and Environmental Physiology 161, 602-610. 
Sigle, L.T., Hillyer, J.F., 2016. Mosquito hemocytes preferentially aggregate and phagocytose pathogens in the periostial regions of the heart that experience the most hemolymph flow. Dev Comp Immunol 55, 90-101.

Slama, K., 2006. Heartbeat reversal after sectioning the dorsal vessel and removal of the brain of diapausing pupae of Manduca sexta (Lepidoptera : Sphingidae). Eur J Entomol 103, 17-26.

Slama, K., Lukas, J., 2011. Myogenic nature of insect heartbeat and intestinal peristalsis, revealed by neuromuscular paralysis caused by the sting of a braconid wasp. J Insect Physiol 57, 251-259.

Swale, D.R., Engers, D.W., Bollinger, S.R., Gross, A., Inocente, E.A., Days, E., Kanga, F., Johnson, R.M., Yang, L., Bloomquist, J.R., Hopkins, C.R., Piermarini, P.M., Denton, J.S., 2016. An insecticide resistance-breaking mosquitocide targeting inward rectifier potassium channels in vectors of Zika virus and malaria. Sci Rep 6, 36954.

Uhde, I., Toman, A., Gross, I., Schwanstecher, C., Schwanstecher, M., 1999. Identification of the potassium channel opener site on sulfonylurea receptors. J Biol Chem 274, 28079-28082.

Wasserthal, L.T., 1996. Interaction of circulation and tracheal ventilation in holometabolous insects. Adv Insect Physiol 26, 297-351.

Zornik, E., Paisley, K., Nichols, R., 1999. Neural transmitters and a peptide modulate Drosophila heart rate. Peptides 20, 45-51. 

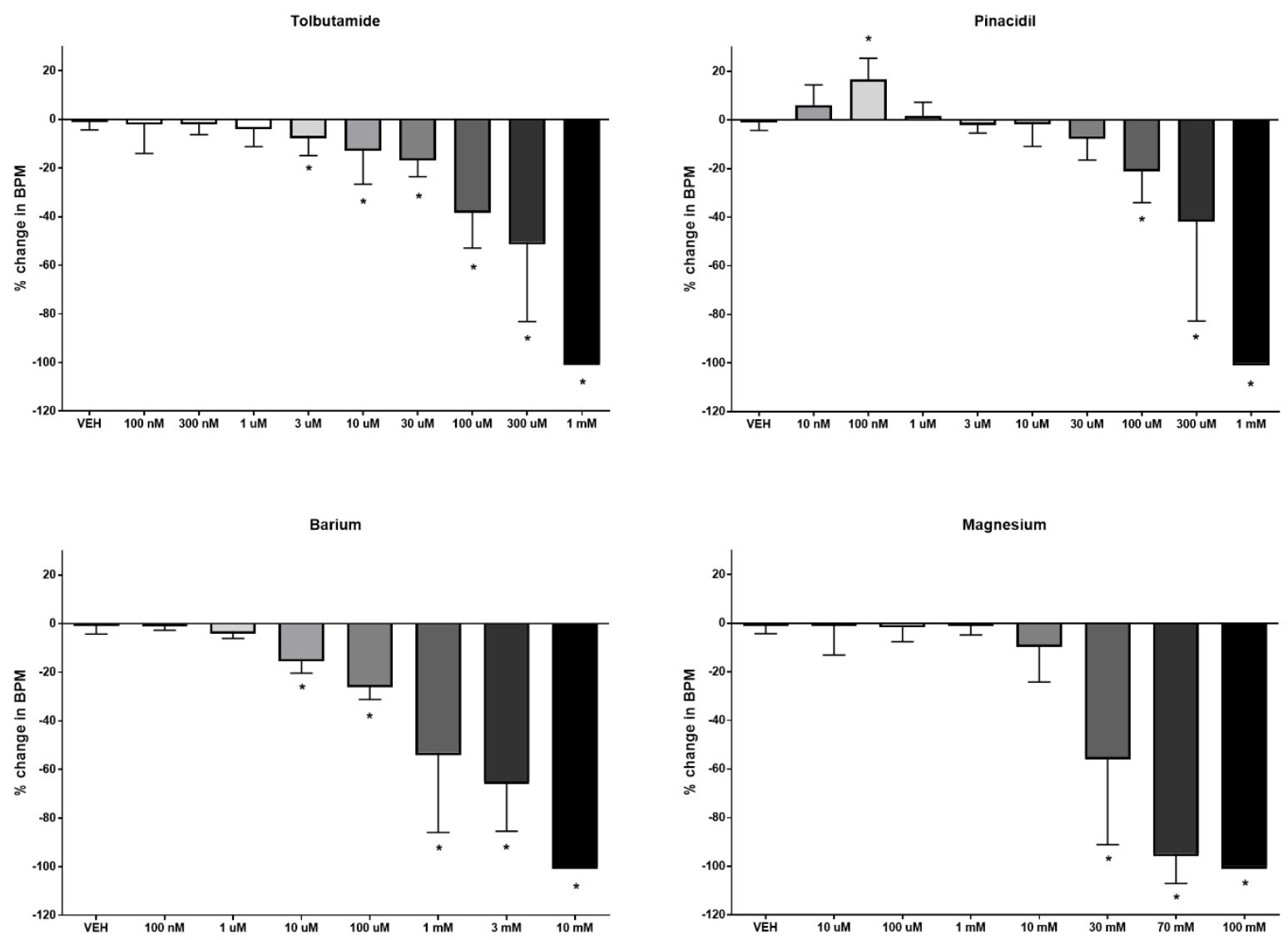

Figure 1. Bar graphs of the percent change in heart rate (beats per minute, BPM) resulting from the application of increasing concentrations of tolbutamide, pinacidil, barium, and magnesium. Relative to a vehicle control (VEH $=1 \%$ DMSO v/v in Ringer's solution), heart rate decreased in a concentration-dependent manner with the application of increasing concentrations of tolbutamide, barium, and magnesium, whereas heart rate increased with the application of a low concentration of pinacidil, but decreased at higher concentrations. The mean values were compared to a vehicle control using a Mann-Whitney nonparametric unpaired $t$-test where $P<0.05$ was considered significant, as represented by an asterisk. Data presented as mean values +/- standard deviation $(n=10)$ and analyzed using GraphPad Prism 7 software. 


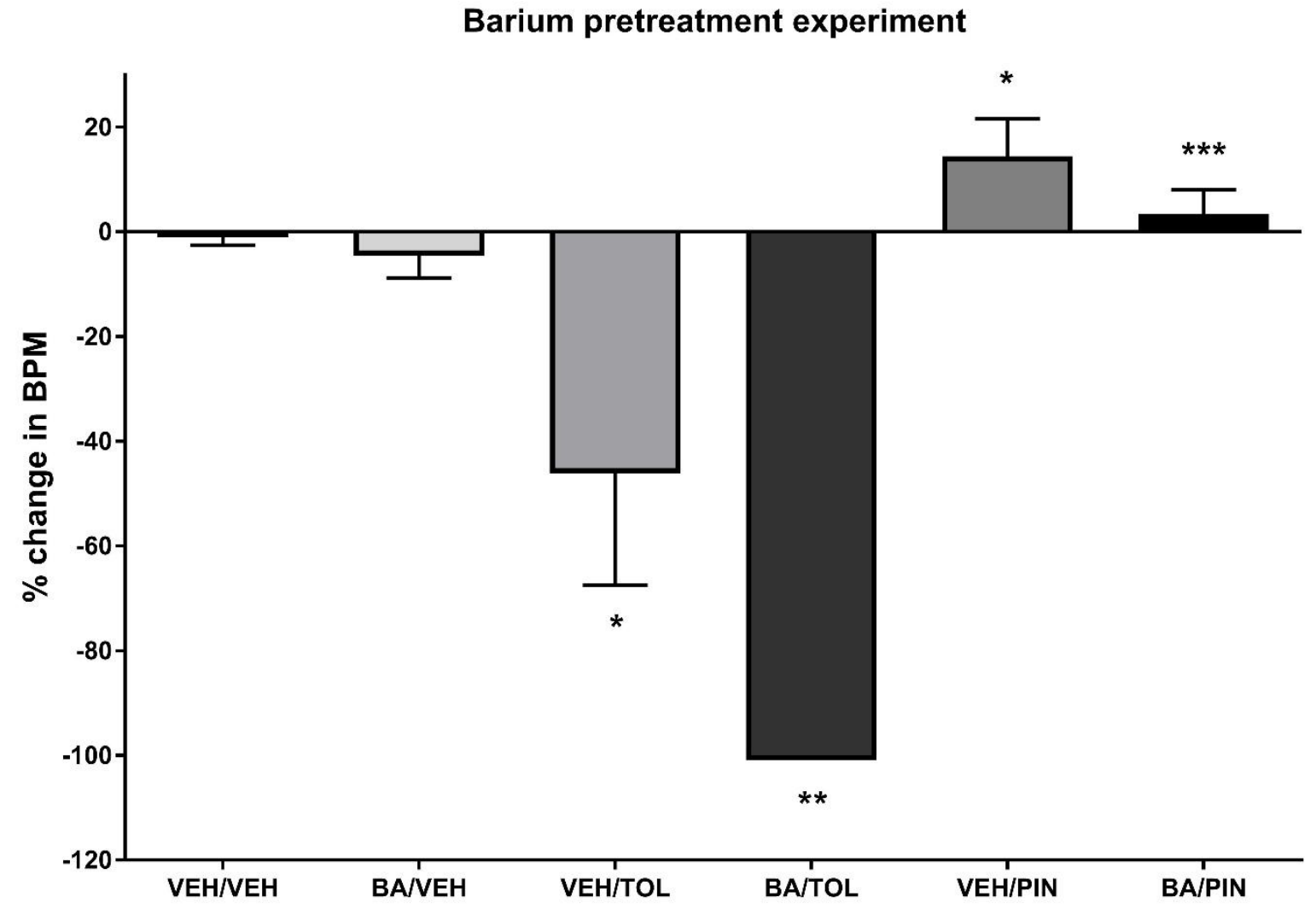

Figure 2. Bar graph of the percent change in heart rate (beats per minute, BPM) resulting from the application of barium followed by tolbutamide or pinacidil. Application of a low concentration of barium $(B A=1 \mu \mathrm{M})$ followed by vehicle (VEH $=1 \%$ DMSO v/v in Ringer's solution) resulted in no significant change in heart rate, relative to a vehicle/vehicle control. Application of vehicle followed by tolbutamide (TOL $=100 \mu \mathrm{M})$ decreased heart rate while vehicle followed by pinacidil (PIN = $100 \mathrm{nM}$ ) increased heart rate. Application of barium followed by tolbutamide resulted in a greater decrease in heart rate than observed with tolbutamide alone. Application of barium followed by pinacidil resulted in no significant change in heart rate, relative to a vehicle control, which was significantly lower than vehicle/pinacidil group. Mean values were compared using a Mann-Whitney nonparametric unpaired $t$-test where $P<0.05$ was considered significant, with significant difference from vehicle control group represented by an asterisk. Double asterisk indicates that mean value is significantly different from both vehicle control and vehicle/tolbutamide groups. Triple asterisk indicates that mean value is not significantly different from vehicle control group, but is significantly different from vehicle/pinacidil group. Data presented as mean values +/- standard deviation $(n=12)$ and analyzed using GraphPad Prism 7 software. 

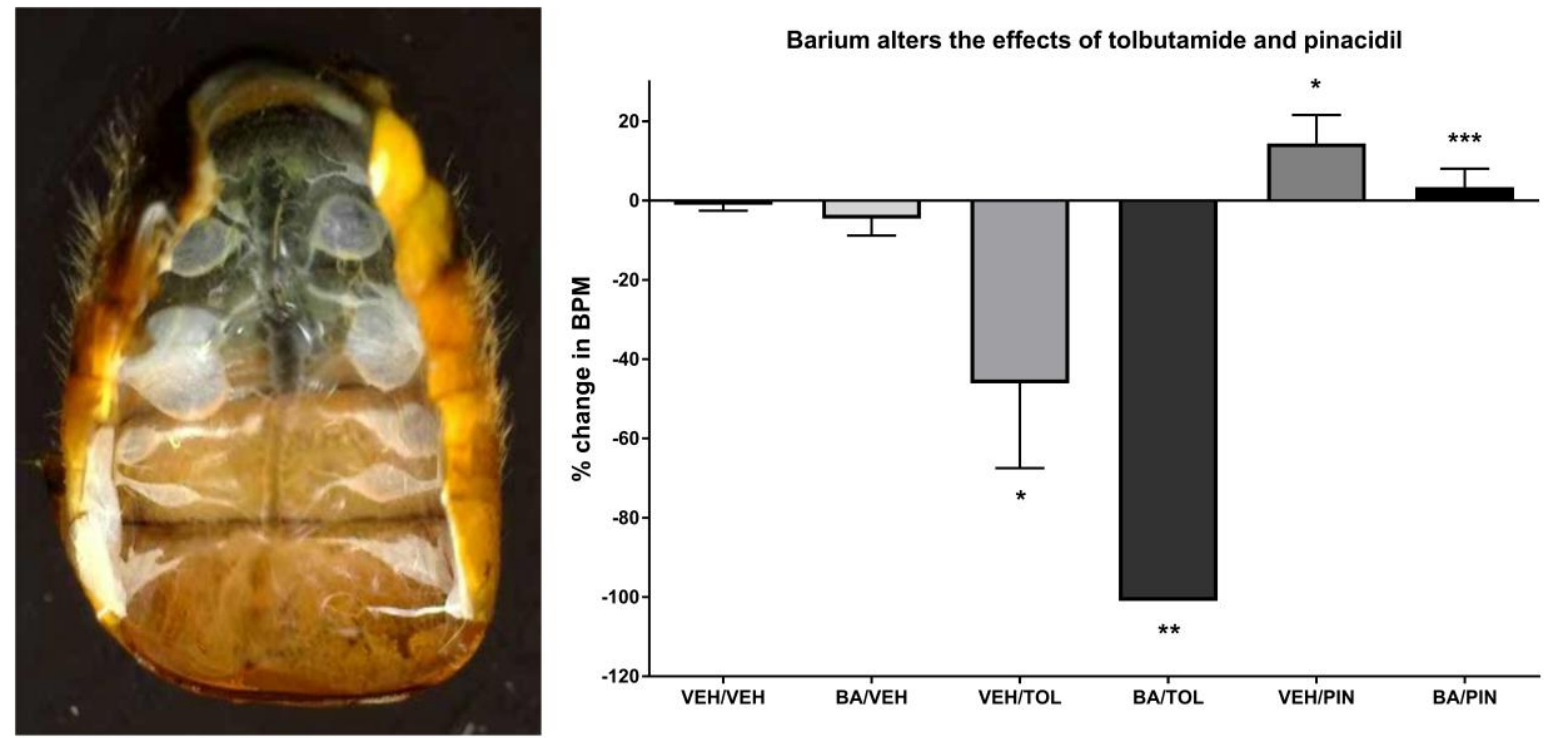